\title{
Do paleontologists dream of electric dinosaurs? Investigating the presumed inefficiency of dinosaurs contact incubating partially buried eggs
}

\author{
Jason D. Hogan (D) and David J. Varricchio
}

\begin{abstract}
Troodon formosus, a theropod from the Late Cretaceous, is one of the few species of dinosaurs with multiple nest sites uncovered. It has been consistently demonstrated that eggs within these nests would have been partially buried in life - an exceedingly rare state in modern vertebrates. There has been debate over Troodon's capacity to engage in thermoregulatory contact incubation, especially regarding an adult's ability to efficiently supply partially buried eggs with energy. An actualistic investigation was undertaken to determine the thermodynamic efficiency of contact incubating partially buried eggs. An efficient system would keep eggs at temperatures closer to the surrogate parent than the ambient, without prohibitively high energy input. For the experiment, a surrogate dinosaur was created and used in both indoor controlled ambient temperature trials and in an outdoor variant. Even with ambient temperatures that were likely cooler than Cretaceous averages, the results showed that contact incubating partially buried eggs did seem to confer an energetic advantage; egg temperatures remained closer to the surrogate than ambient in both indoor and outdoor tests. Still, critics of contact incubating partially buried eggs are correct in that there is a depth at which adult energy would fail to make much of an impact-perhaps more relevant to buried eggs, as partially buried eggs would be in contact with an adult and likely above the thermal input threshold. Additionally, results from this experiment provide evidence for a possible evolutionary path from guarding behavior to thermoregulatory contact incubation.
\end{abstract}

Jason D. Hogan and David J. Varricchio. Department of Earth Sciences, Montana State University, Bozeman, Montana 59717, U.S.A. E-mail: m88s833@msu.montana.edu,djv@montana.edu

Accepted: 12 September 2020

\section{Introduction}

Our understanding and interpretation of theropod dinosaurs has progressed from originally reptilian to increasingly more avian. Many features we previously thought unique to modern birds have now been found in their dinosaur ancestors (Chiappe 2009). However, behavioral interpretations remain challengingprincipal among these are nesting behaviors. Currently there is no consensus on whether maniraptoran theropod dinosaurs employed thermoregulatory contact incubation, passive incubation, or simply nest guarding (Varricchio et al. 1999; Grellet-Tinner et al. 2004). Perhaps all of these behaviors were present in one group of theropods or another, but it is not clear for oviraptorids and troodontids-the groups with the most nest-related fossils. These fossils include adult material associated with eggs (Norell et al. 1995, 2018; Varricchio et al. 1997; Fanti et al. 2012) as well as embryonic remains (Norell et al. 1994, 2001; Varricchio et al. 2002). Some authors argue that evidence suggests parents were engaged in active incubation (Varricchio et al. 2013, 2018). Others are dubious of such behavior, and believe that nest guarding of buried eggs was more likely (Wesołowski 2004; Deeming 2006; Jones and Geist 2012; Yang et al. 2019b).

For Troodon in particular, one major criticism of contact incubation is the presumed inefficiency of incubating partially buried eggs (Ruben et al. 2003). Several fossilized egg clutches have been linked with Troodon formosus (Varricchio et al. 1999, 2002) and nest attendance behavior (Varricchio et al. 1997). These Troodon nest sites consistently feature eggs that would have been partially buried in life (Horner and Weishampel 1988; Varricchio et al. 1997). Partial burial is further supported by analysis of eggshell porosity that shows

(C) The Author(s), 2020. Published by Cambridge University Press on behalf of The Paleontological Society. This is an Open Access article, distributed under the terms of the Creative Commons Attribution licence (http://creativecommons.org/ licenses/by/4.0/), which permits unrestricted re-use, distribution, and reproduction in any medium, provided the $\cdots$ - : $:-1-1$ 
differing pore densities along the length of the egg (Varricchio et al. 2013). Many modern reptiles and some modern birds incubate their eggs using energy generated from mounds of decaying vegetation, and although this has been suggested as a possibility for Troodon, there is no geologic evidence for plant material in the nest (Varricchio et al. 1999). Partial burial of eggs is rarely practiced by extant vertebrates. The most well-known example is the Egyptian plover (Pluvianus aegyptius) (Grellet-Tinner et al. 2006); though this may not be an appropriate comparison. The Egyptian plover inhabits hot, dry African climates where it exhibits the specialized behavior of egg thermoregulation via evaporative cooling. It has been suggested that perhaps Troodon engaged in similar behavior (Grellet-Tinner et al. 2006), but in dinosaurs partially buried nests may represent intermediate behavior instead. After all, if complex behavior can evolve incrementally through generations (Lorenz 1958; Gould 1982; Gomez and Miikkulainen 1997), then an ancestor of modern birds likely did use partialburial nesting strategies (as ancestral reptiles used subterranean nests and modern birds tend to build subaerial ones) (Varricchio and Jackson 2016). Still, the question remains as to whether or not these partially buried nests coincided with contact incubation.

Because questions about the inefficiency of partially buried eggs cannot be satisfactorily addressed by comparisons to modern reptiles and birds or through strict geologic data, an actualistic study was devised to examine the viability of the behavior, with regard to energy efficiency, in both an indoor controlled mocknesting environment and an outdoor system. Models can serve as appropriate placeholders when past systems differ significantly from what can be observed in modern organisms. Although approximations of past behavior or physiology will always suffer from assumptions, such models still provide researchers with a foothold for further research. These investigations have become an increasingly useful way for paleontologists to explore prehistoric processes. Some examples include assessments of the airflow and thermoregulation regarding the plates of Stegosaurus (Farlow et al. 1976), the sail of Edaphosaurus (Bennett 1996), and
Microraptor flight capabilities (Alexander et al. 2010; Dyke et al. 2013; Palmer 2014).

This purpose of this experiment is to investigate whether or not incubating partially buried eggs through contact is efficient enough that the two behaviors could have coincided. For the purpose of this study, inefficiency constitutes a system where energy input from the adult is so high as to render the feat infeasible, or energy leaches from the eggs to the sediment at a rate great enough to hinder the eggs' capacity to consistently maintain temperatures above that of the air or soil. So, an inefficient system is one where an adult sitting on the eggs confers no thermodynamic advantage (i.e., warmer or more regular temperatures) compared with non-incubated subaerial or non-incubated shallow subterranean nest states. Temperature plays a critical role in the duration of egg-bound embryo development (Szczerbińska et al. 2003; DuRant et al. 2013); even a marginal increase over ambient temperature could result in shorter incubation periods. Shorter incubation periods mean that adult animals can be free of the nest sooner, whether they are incubating or guarding.

A key assumption of this experiment is that Troodon and its relatives were endothermic. Although a few modern ectotherms do contact incubate (Stahlschmidt and Denardo 2009), it seems unlikely that Troodon shared these specialized behaviors. Histological evidence does support endothermy in Troodon (Varricchio 1993). Additionally there is ample evidence to suggest that endothermy was widespread in dinosaurs, theropods specifically (Barrick and Showers 1994; Fricke and Rogers 2000; Amiot et al. 2006; Eagle et al. 2011). Recent research on troodontid body temperatures provides an estimated range of $28^{\circ} \mathrm{C}-38^{\circ} \mathrm{C}$ (Dawson et al. 2020). Ten degrees is a substantial difference, and a narrower band $\left(35^{\circ} \mathrm{C}-40^{\circ} \mathrm{C}\right)$ has been proposed for the closely related oviraptorosaurs (Amiot et al. 2017). These temperatures fall within the range of modern birds, including emus (Dromaius novaehollandiae) and ostriches (Struthio camelus), terrestrial birds of comparable sizes to troodontids and oviraptorosaurs (Szczerbińska et al. 2003; Hassan et al. 2004).

Furthermore, despite the fact that no feather fossils can currently be directly assigned to 
T. formosus, it is assumed that it had feathers similar to those found in other troodontids, oviraptorosaurs, and indeed theropods in general (Hopp and Orsen 2004; Barrett et al. 2015). This assumption is important in that feathers would have provided insulative benefits for the nest microenvironment. This experiment does not attempt to investigate endothermy or the presence of feathers in Troodon. Instead, the purpose is to investigate the efficiency of contact incubating partially buried eggs under the assumptions that adults exhibited some form of endothermy and insulation.

Nomenclatural Note.-There has been some discussion on the validity of the name Troodon formosus. Most recently, van der Reest and Currie (2017) have suggested abandoning the name, reverting to Stenonychosaurus inequalis (a junior synonym), and designating a neotype. The name T. formosus is still used herein, as only the International Commission on Zoological Nomenclature can make a neotype ruling while an original holotype exists (ICZN 1999: art. 75). Furthermore, the continued use of the T. formosus supports stability - the underlying goal of the ICZN.

\section{Methods}

To investigate this brooding conundrum, an artificial system was constructed to replicate a nesting microenvironment similar to what might have been present for Troodon. A sediment-filled box was used during the indoor trials to represent a nesting location. Figure 1A shows the box, with eggs in the middle. These were nonviable chicken eggs with inserted thermometers. Additional thermometers were placed at various depths in the sediment, outside the experimental box for ambient temperatures, and within the air gap of the microenvironment. In this experiment, the air gap is the space between the two eggs, under the surrogate, and above the sediment. A surrogate dinosaur was created using a vinyl-held water bath warmed by an aquarium heater. This surrogate had a layer of insulation around the outside, top, and edges of the bottom. After controlled indoor trials, the same surrogate was used to conduct a similar test outside. In

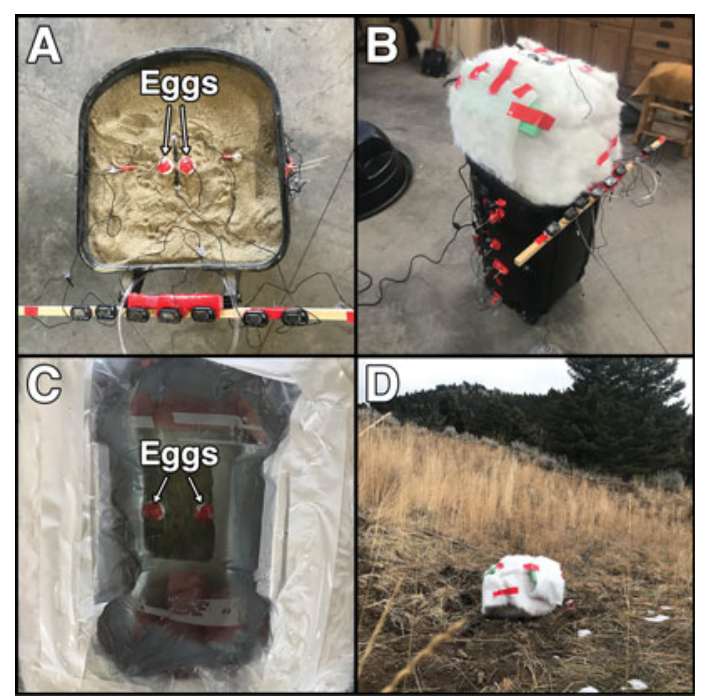

FIGURE 1. Photo series showing the surrogate dinosaur incubator, indoor sediment setup, and outdoor setup. The sediment container was $43 \times 50 \times 80 \mathrm{~cm}$. The surrogate measured approximately $53 \times 41 \times 41 \mathrm{~cm}$. A, A bird's-eye view of the sediment container, eggs, surface probes, and thermometer displays. In the final runs, the thermometer displays were localized and adhered to the side of the sediment container for ease of data capture. B, The surrogatean insulated soft vinyl water container with water heateron top of the sediment container. C, The eggs can be seen below the surrogate through the water held within the vinyl when the lid, insulation layer, and aquarium heater are removed (bird's-eye view). Tape covers the top to keep the thermometers in place within the eggs. D, An image of the surrogate outside in the testing area near Bozeman, Montana, at an elevation around $1850 \mathrm{~m}$.

a natural setting the ground is a practically infinite heat sink - its overall temperature will not change no matter how long an incubating parent rests there. The local temperature does change though, and energy will continually flow from the adult into the surrounding nest and from the nest into deeper earth.

The indoor experimental system was of a size and situation such that energy could continually flow from the surrogate into the environment without raising ambient temperature. If too small, the environment will slowly heat up and provide skewed results. This state can be assured if the periphery sediment maintains a similar temperature to that of the ambient throughout the experiment. If this is the case, then the total effective heating zone of the surrogate dinosaur can be investigated. 
A $43 \times 50 \times 80 \mathrm{~cm}$ plastic container was filled with approximately $272 \mathrm{~kg}$ of multipurpose sand (Sakcrete brand). Grains were well mixed and ranged from clay to coarse sand, with a small amount of gravel as well. Paleosols from the Two Medicine Formation were thought to be representative of well-drained soils (Retallack and Wolberg 1997), and a lack of soil moisture is further evidenced by the abundance of fossil pupa cases found in that horizon (Martin and Varricchio 2011; Freimuth and Varricchio 2019). Accordingly, the sediment for this experiment was kept dry. The sediment container rested on a solid cement floor in a temperature-controlled room. No basement, floors, or utilities were located below the experimental area. Room temperature was set to $15.5^{\circ} \mathrm{C}$ and monitored independently of the thermostat.

A representative surrogate dinosaur was imagined as a heated water bath (Fig. 2). This bath was constructed out of PVC framing that held a vinyl-lined interior filled with approximately $19 \mathrm{~kg}$ of water. Vinyl was chosen as a soft water-holding material that could contact the eggs without undue pressure - similar to skin. The water bath itself was wrapped with approximately $3 \mathrm{~cm}$ of home insulation on the sides, top, and bottom edges. The egg contact
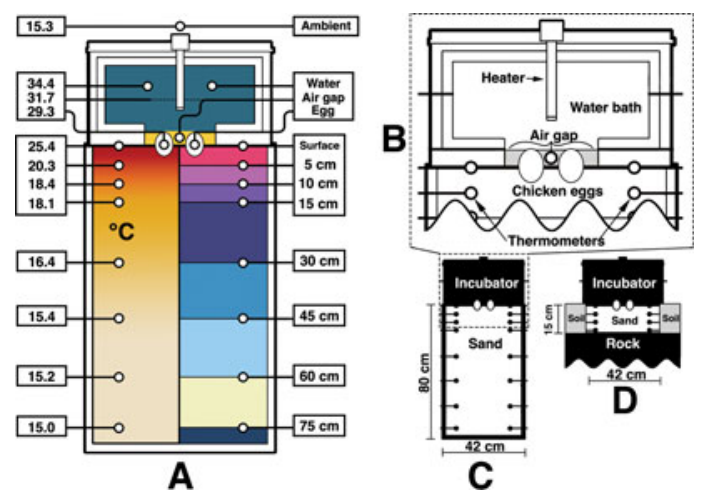

FIGURE 2. Diagram of the surrogate incubator and sediment container. A, A cross section of the experiment with temperatures $\left({ }^{\circ} \mathrm{C}\right)$ corresponding to those recorded at 72 hours (left). The right side of A shows the location of temperature-probe groups. Divisions correspond to those used in Figs. 3-5. B, A simplified pullout of the surrogate incubator, eggs, and sediment interface. C, Dimensions of the sediment container. D, The surrogate over the sandfilled chamber in the outside setup. face was left as just vinyl. Importantly, no insulation was used in the box that held sediment. The outside of the surrogate was wrapped in soft liner to help hold the insulation together. Final dimensions of the surrogate were approximately $53 \times 41 \times 41 \mathrm{~cm}$. An aquarium heater (Hygger 200 watt submersible heater) heated the water bath to $36.8^{\circ} \mathrm{C}$ (which equalized to $34.4^{\circ} \mathrm{C}$ ) for the indoor trials and $35^{\circ} \mathrm{C}$ (which equalized to approximately $29^{\circ} \mathrm{C}$ ) for the outdoor.

Temperature probes (Aquaneat aquarium digital thermometers) were tested beforehand for regularity among each other and in different substrates, as they themselves could not be independently calibrated. All thermometers measured within $0.3^{\circ} \mathrm{C}$ from the median during the indoor trials and $0.5^{\circ} \mathrm{C}$ for the outdoor. For the ambient temperature controlled indoor experiment, a total of 25 thermometers were used. Two were placed at each measurable location: the water bath of the surrogate, air ambient, eggs (one thermometer in each), interior nest air gap, surface, and then within the sediments at depths of $5 \mathrm{~cm}, 10 \mathrm{~cm}, 15 \mathrm{~cm}, 30 \mathrm{~cm}$, $45 \mathrm{~cm}, 60 \mathrm{~cm}$, and $75 \mathrm{~cm}$. Locations are shown in Figure 2A along with final temperatures recorded at those locations after 72 hours. Temperatures were recorded for 72 hours for the indoor trials and 48 hours for the outdoor. Energy input was recorded via a plug-in kilowatt-hour electricity monitor (Poniie PN2000) that all electrical energy flowing into the system passed through.

The same surrogate dinosaur was used for the outdoor trials. A hole was dug outside with a length and width slightly greater than that of the surrogate dinosaur. It was dug to a depth of $15 \mathrm{~cm}$ and filled with the same sand. The hole only extended slightly $15 \mathrm{~cm}$ due to the shallow soil profile and close bedrock. Thus, the bottom of the sand-filled hole was partially in contact with the rock. This created a local nesting environment likely less favorable than a troodontid would have used, as nest energy would leach faster through solid rock than air-pocketed sand and sediment. Regardless, $15 \mathrm{~cm}$ was the experimental zone to be investigated, as the majority of thermal fluctuation during the indoor experiments fell within this distance. Once the hole was dug 
and filled, thermometers were placed to measure temperatures at depths of $5 \mathrm{~cm}, 10 \mathrm{~cm}$, and $15 \mathrm{~cm}$. Additional thermometers were positioned to measure the surrogate, air ambient, eggs, interior nest air gap, and the surface sediment.

The eggs selected for this experiment were store-bought chicken eggs, each with a mass of $56 \mathrm{~g}$. These eggs were vertically oriented and buried halfway in the sediment. For this study the embryos were nonviable, as only temperature was being investigated. Developmental rate of embryos is directly related to temperature, so examination of temperature potentially provides information on those rates (Szczerbińska et al. 2003). Holes were tapped into the tops of the eggs to allow thermometers to be placed inside, and then the holes were sealed over.

To get an idea of possible egg temperatures from higher-temperature incubation situations, the average ambient temperature was compared with the average surrogate temperature over the final 16 hours of each trial. The difference between the surrogate maximum and ambient minimum was then calculated and compared with difference between the average egg temperatures and ambient temperatures for those time periods. These two differences were then compared to arrive at a useful percentage value. This value takes the disparity between the ambient and body-surrogate temperature into account, providing a more useful contrast than the arbitrary designation of $0^{\circ} \mathrm{C}$ as the temperature floor (and any comparisons using kelvin are compressed and misleadingly similar due to the additional 273 degrees). With these values derived, hypothetical temperature ranges for different ambient

TABLE 1. Derived approximate egg temperatures for different ambient-body temperature combinations. Actual experimental body, ambient, and egg temperatures are italicized. 10.0 $=$ Cretaceous Arctic cool, temperate coldest month, outdoor experimental; $15.7=$ Cretaceous Arctic moderate, indoor experimental; 22.0 = Cretaceous Arctic warm, temperate moderate; $27.0=$ temperate warm; 29.0 = temperate hot

\begin{tabular}{lccccc}
\hline \hline Ambient in ${ }^{\circ} \mathrm{C}$ & 10.0 & 15.7 & 22.0 & 27.0 & 29.0 \\
Body $40.0^{\circ} \mathrm{C}$ & 33.9 & 35.1 & 35.7 & 36.3 & 37.4 \\
Body $35.0^{\circ} \mathrm{C}$ & 29.9 & 31.1 & 31.8 & 32.4 & 33.4 \\
Body $34.4^{\circ} \mathrm{C}$ & - & 29.3 & - & - & - \\
Body $29.2^{\circ} \mathrm{C}$ & 25.9 & - & - & - & - \\
\hline
\end{tabular}

environments were calculated alongside $35^{\circ} \mathrm{C}$ and $40^{\circ} \mathrm{C}$ incubators (Table 1 ).

The slopes of the best-fit lines were compared to ascertain the similarity of the rates of change between the indoor and outdoor trials. If the rates are equal, then the slopes would be identical and the lines parallel. A normalized dot product calculation was used to test how close to parallel each line was. The dot product (U.V) of the two vectors ( $\mathbf{U}$ and $\mathbf{V}$ ) can be found with:

$$
\begin{aligned}
& \mathbf{U} \cdot \mathbf{V}=\left(\mathbf{U}_{x}\right)\left(\mathbf{V}_{x}\right)+\left(\mathbf{U}_{y}\right)\left(\mathbf{V}_{y}\right), \\
& \text { where } \mathbf{U}=\left\langle\mathbf{U}_{x}, \mathbf{U}_{y}>\text { and } \mathbf{V}=\left\langle\mathbf{V}_{x}, \mathbf{V}_{y}>\right.\text {. }\right.
\end{aligned}
$$

If the vectors are first normalized, then a resulting dot product of 1 means the lines are exactly parallel, whereas a dot product of 0 means they are orthogonal. Vectors were taken from the trend lines of the rising egg temperatures from the first hour of the indoor $\left(y_{i}=0.573 x+17\right)$ and outdoor $\left(y_{0}=0.817 x+\right.$ 11.9) trials. This was repeated for the trend lines from hours 8 to $48\left(y_{\mathrm{i}}=0.184 x+28.3\right.$ and $\left.y_{\mathrm{o}}=0.319 x+24.3\right)$.

These experiments were conducted outside the city of Bozeman, Montana, at an elevation of approximately $1850 \mathrm{~m}$. The outdoor trials occurred during the week of October 6, 2019. Temperature readouts were recorded, tabled, and graphed within Microsoft Excel. Figures were compiled in Adobe Photoshop.

\section{Results}

\section{Indoor Trials}

During indoor tests the water bath temperature dropped from $36.8^{\circ} \mathrm{C}$ (Fig. 3). After 1 hour it was down to $33.7^{\circ} \mathrm{C}$, and it stayed within $\pm 0.7^{\circ} \mathrm{C}$ until the end of the 72 hour run. The ambient temperature fluctuated between $17^{\circ} \mathrm{C}$ and $14.9^{\circ} \mathrm{C}$ with a median of $15.7^{\circ} \mathrm{C}$. Egg temperature began at $16.2^{\circ} \mathrm{C}$ and rose to $23.4^{\circ} \mathrm{C}$ within one hour. It continued to rise up to $29.3^{\circ} \mathrm{C}$ by 56 hours and stayed there until 72 hours. Average egg temperature was closer to that of the water bath/surrogate than ambient by 2 hours into the trial and remained there until the end.

The temperature of the air gap between the surrogate and the sediment surface was the 

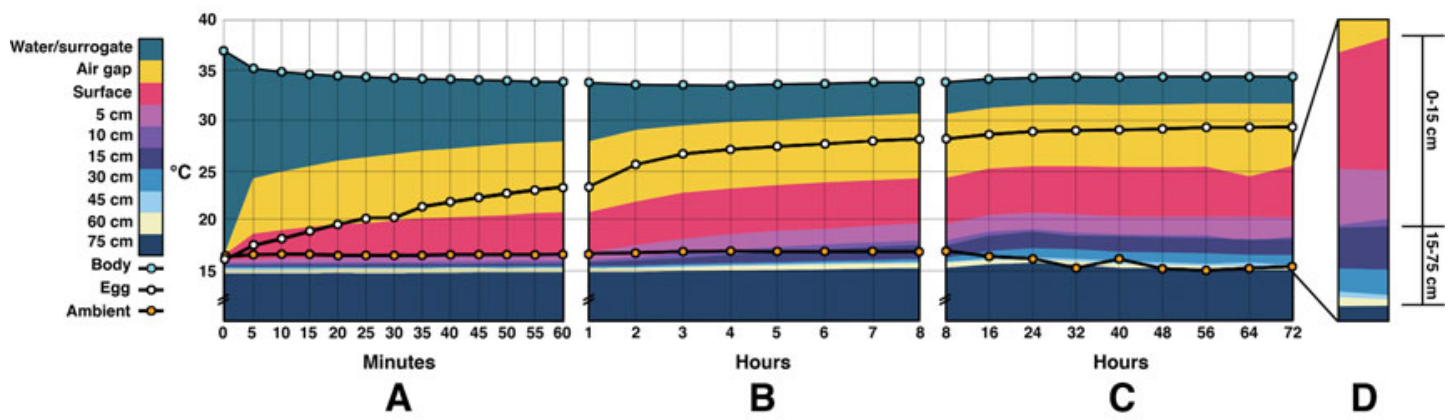

FIGURE 3. Combination area and line graphs showing energy throughout the temperature-controlled indoor experiments. Values averaged between probes at the same locations. An area chart is used to show the difference in temperatures between two adjacent zones. Actual temperature values are tracked by the upper border of a color (water/surrogate and body temperature being the same - body temperature is emphasized for comparison to egg and ambient). A, Readings during the first 60 minutes of testing. It is difficult to visually differentiate depths below $15 \mathrm{~cm}$ due to the closeness of temperatures. B, Rising temperatures over hours 2 through 8. C, Data begin at 8 hours and ends at 72 hours. The y-axis is the same throughout. D, Pullout highlighting the difference in energy within the first $15 \mathrm{~cm}$ of sediment vs. the remaining $60 \mathrm{~cm}$. After 2 hours of incubation, egg temperatures remain closer to the water/surrogate than ambient temperatures. Note that the y-axis base is truncated to better show changing temperatures.

only area warmer than the eggs after 20 minutes of testing. By 24 hours, this temperature was $31.6^{\circ} \mathrm{C}$, and it stayed within $0.1^{\circ} \mathrm{C}$ until the end of the trial. Within the sediment, the majority of the temperature changes occurred within the first $15 \mathrm{~cm}$. After 72 hours, there was a $7.3^{\circ} \mathrm{C}$ difference between the surface of the sediment and $15 \mathrm{~cm}$, while there was only a $3.1^{\circ} \mathrm{C}$ difference between $15 \mathrm{~cm}$ and $75 \mathrm{~cm}$ (more than half of which was between 15 and $30 \mathrm{~cm}$ ). Temperatures at $60 \mathrm{~cm}$ fell between

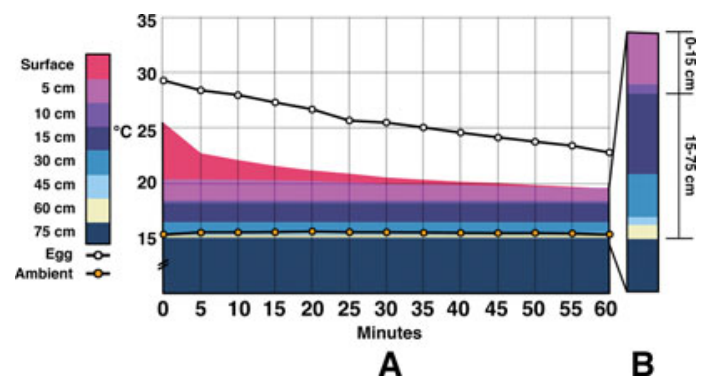

Figure 4. Combination area and line graph showing temperatures once the surrogate had been removed from the sediment container during the indoor trials, hence the omission of water/surrogate temperature. A, Decreasing temperatures over a 60 minute period. Within the first 5 minutes, there is a rapid decline in the temperatures of both the nest air gap and surface sediments. The eggs show a fairly constant decline in temperature throughout the hour. Temperatures at depths below $5 \mathrm{~cm}$ barely fluctuate during this period. B, Pullout showing energy differences within the first $15 \mathrm{~cm}$ vs. the remaining $60 \mathrm{~cm}$ (contrast with Fig. 3D) $15.1^{\circ} \mathrm{C}$ and $16.0^{\circ} \mathrm{C}$ with a median of $15.5^{\circ} \mathrm{C}$. Values at $75 \mathrm{~cm}$ were similar, ranging between $14.7^{\circ} \mathrm{C}$ and $15.7^{\circ} \mathrm{C}$ with a median of $15.2^{\circ} \mathrm{C}$. During the course of the experiment, the water heater warming the surrogate used on average $22.7 \mathrm{kcal} / \mathrm{h}$.

After the completion of the 72 hour run, the surrogate was removed from the sediment container, and cool-down temperatures were recorded for 8 hours (Fig. 4). Surface temperature fell rapidly over the first 30 minutesfrom $25.4^{\circ} \mathrm{C}$ to $20.4^{\circ} \mathrm{C}$. All sediment temperatures below $5 \mathrm{~cm}$ changed $0.1^{\circ} \mathrm{C}$ or less over the first hour. Egg temperatures dropped from $29.3^{\circ} \mathrm{C}$ to $25.5^{\circ} \mathrm{C}$ in the first half hour, and then down to $22.75^{\circ} \mathrm{C}$ after an hour. Within 5 hours, all temperatures were within approximately $2.5^{\circ} \mathrm{C}$ of ambient values.

Outdoor Trials.-Water temperature during the outdoor portion of this experiment began at $35^{\circ} \mathrm{C}$ and stabilized around $29^{\circ} \mathrm{C}$ by 3 hours (Fig. 5). It then fluctuated $\pm 0.7^{\circ} \mathrm{C}$ for the remainder of the experiment. Ambient temperature was highly variable throughout the day, with a recorded high of $22.5^{\circ} \mathrm{C}$ and a low of $2.1^{\circ} \mathrm{C}$. The median was $9.8^{\circ} \mathrm{C}$. Egg temperature rose steadily, beginning at $10.7^{\circ} \mathrm{C}$ and reaching $20.7^{\circ} \mathrm{C}$ by the first hour. The eggs fluctuated between $24^{\circ} \mathrm{C}$ and $26.5^{\circ} \mathrm{C}$ after the fifth hour and continued to do so throughout the remainder of the trial. 


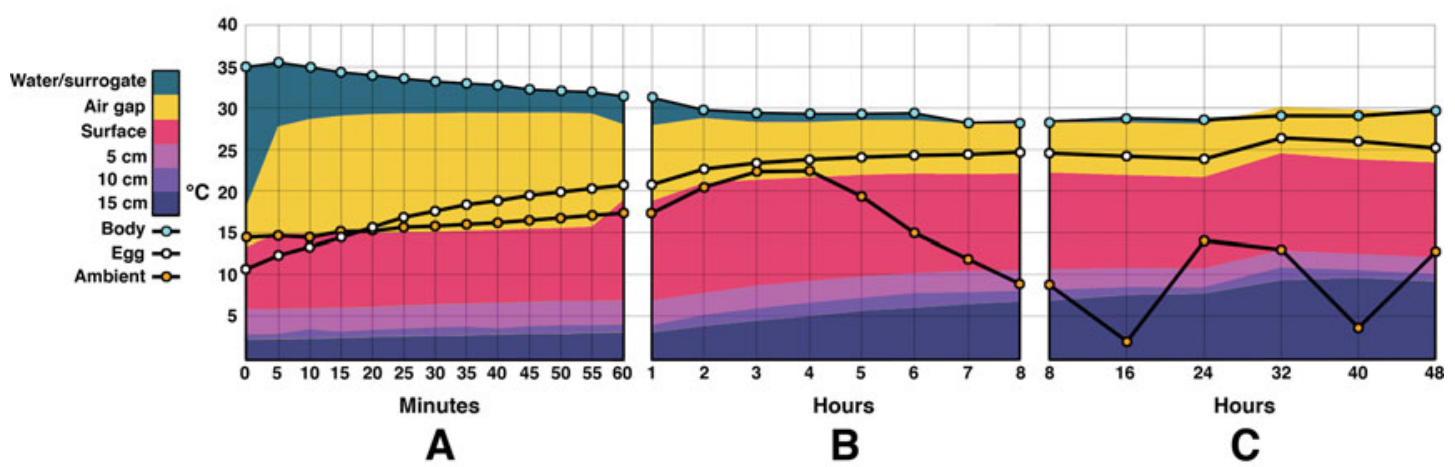

FIGURE 5. Combination area and line graphs showing energy flow during the outdoor experiments. Time zero was noon. Temperatures at depths below $15 \mathrm{~cm}$ were not measured for this experiment. A, Temperatures during the first 60 minutes. Water/surrogate temperature decreases steadily while egg temperatures rise. Sediment temperatures rise slowly. B, Temperature changes from the 1 hour to 8 hour mark. The water/surrogate temperature mostly levels off after a few hours. Sediment and egg temperatures continue to rise. Ambient temperature rises until 4 P.M. and then begins decreasing. C, The remaining 40 hours after the initial 8 hour test set. The nest air gap temperature briefly overtakes the water temperature, possibly due to a discrepancy in the insulation of the water bath vs. the egg chamber. Ambient temperature fluctuates daily, while the water/surrogate temperature remains fairly constant. Egg temperatures remain close to water/surrogate despite fluctuating ambient temperatures. Note that the y-axis is not truncated as in Fig. 3.

The temperature of the air gap rose faster and stayed higher than those of the eggs. It jumped from $18.1^{\circ} \mathrm{C}$ to $28.6^{\circ} \mathrm{C}$ within the first $10 \mathrm{~min}$ utes, and then stayed within $1.5^{\circ} \mathrm{C}$ for the rest of the experiment. The temperatures recorded at the $15 \mathrm{~cm}$ depth did rise continuously throughout the experiment, from $2.3^{\circ} \mathrm{C}$ to $9.65^{\circ} \mathrm{C}$ at 40 hours, falling back about $0.5^{\circ} \mathrm{C}$ by 48 hours. During the outdoor trials the water heater used an average of $18.27 \mathrm{kcal} / \mathrm{h}$.

Table 1 was created to show possible egg temperatures for ambient-body temperature combinations beyond the scope of this study. Values were calculated by comparing the difference between ambient and egg temperatures with the difference between ambient and body temperatures (see "Methods"). The following values were derived for warmer incubators and differing ambient environments. An incubating adult with a body temperature of $35^{\circ} \mathrm{C}$ would possibly see egg temperatures of $29.9^{\circ} \mathrm{C}$ to $33.4^{\circ} \mathrm{C}$, while an incubator with a body temperature of $40^{\circ} \mathrm{C}$ would have egg temperature ranges of $33.9^{\circ} \mathrm{C}$ to $37.4^{\circ} \mathrm{C}$ (Table 1).

\section{Discussion}

Actualistic investigations will always include assumptions and generalizations, and their results should be interpreted carefully. For these experiments it was assumed that an incubating Troodon-like animal would be endothermic with an insulating integumental covering. Because the purpose of this study was to test the thermal properties of partially buried eggs, a nest structure was not replicated. Trace fossils linked to T. formosus show nests with a circular raised rim (Varricchio et al. 1997). While nest structure certainly affects egg microclimate, it was outside the scope of this study. Regarding insulation, final temperatures from the trials showed that eggs maintained a temperature difference from the ambient that was $75.6 \%$ of what the surrogate maintained for the indoor trials and $83.1 \%$ for the outdoor. These percentages were calculated by finding the difference between the egg and ambient temperatures, then dividing it by the difference between the surrogate and ambient temperatures (same technique used for Table 1). Temperature recordings within active eider (Somateria mollissima) and barnacle goose (Branta leucopsis) nests (Rahn et al. 1983) found that the eggs hovered around $84.3 \%$ and $86.8 \%$, respectively, when compared with ambient and body temperatures in the same manner. Although this may be coincidental due to the large difference in parental mass and nest structure, the similar ratios suggest that the surrogate dinosaur is not unrealistically efficient. 
Egg temperatures did equalize more closely to surrogate values than ambient, but the final egg temperatures (averaged over the final 16 hours of each experiment) for the indoor $\left(29.3^{\circ} \mathrm{C}\right)$ and outdoor $\left(25.9^{\circ} \mathrm{C}\right)$ tests are low for actual incubation. Though it is probable that dinosaurs would have had a lower incubated egg temperature than most modern birds, due to longer incubation times (Varricchio et al. 2018), the experimental values are still likely cooler than actual. These cooler incubation temperatures can be explained by the experimental parameters. First, one limitation of the experiment was the water heater used to warm the surrogate. Once placed on the sediment, the heater struggled to maintain temperatures of $35^{\circ} \mathrm{C}-40^{\circ} \mathrm{C}$. Equalized surrogate temperatures for each of the trials $\left(33.7^{\circ} \mathrm{C}\right.$ indoor and $29^{\circ} \mathrm{C}$ outdoor) were several degrees lower than hypothesized body temperatures for oviraptorosaurs (Amiot et al. 2017), but within the range suggested by Dawson et al. (2020) for troodontids. Though the surrogate temperature was on the low side of the spread, the fact that the eggs still maintained temperatures significantly closer to the water bath than ambient provides strong support for the possibility of incubating partially buried eggs. Energy leaching from the eggs into the sediment did not outpace replenishment from the surrogate, even at these lower temperatures. Higher surrogate or body temperatures would likely raise the temperature at which the eggs would equalize. The discrepancy between set water temperature, starting water temperature, and equalized water temperature was difficult to bridge in this experiment. A more powerful water heater would likely be able to maintain higher and more consistent surrogate temperatures to improve future investigations.

The ambient temperatures used for each experiment were also likely lower than what an incubating T. formosus would have endured. The outdoor average ambient temperature was $9.8^{\circ} \mathrm{C}$, with a low of $2.1^{\circ} \mathrm{C}$. This falls within the range for the coldest month of a temperate climate $\left(-3^{\circ} \mathrm{C}\right.$ to $18^{\circ} \mathrm{C}$ with an average of $10.5^{\circ} \mathrm{C}$ ) (Kottek et al. 2006), and evidence suggests T. formosus lived in a warm temperate climate (Dodson 1971). It is unlikely that this animal would have been incubating during the coldest month of the year. Even the indoor controlled ambient average of $15.7^{\circ} \mathrm{C}$ is likely lower than what $T$. formosus would have experienced during incubation season. Research by Burgener et al. (2019) reconstructs a mean annual range in temperature of $21^{\circ} \mathrm{C}$ to $27^{\circ} \mathrm{C}$ for paleoclimates of the Two Medicine Formation, further suggesting that experimental ambient temperatures were probably lower than actual. Nevertheless, troodontid material has been found in Arctic paleolatitudes (Fiorillo et al. 2009) with warm weather temperatures of $19^{\circ} \mathrm{C}$ (Golovneva 2000). So, while $15.7^{\circ} \mathrm{C}$ might be a reasonable temperature for Arctic incubation, it is likely lower than what more southern troodontids would have experienced in the Cretaceous.

Despite these colder values, the eggs did stay closer to surrogate than ambient temperature after the initial heating phase. The loss of energy to the sediment did not outpace replenishment from the surrogate in either the controlled or outdoor environment. Even with unfavorably cool conditions, contact incubation appears to have conferred a thermodynamic advantage to partially buried eggs. Although Troodon nests lacked the material complexity of modern bird nests, it seems that even a simple air gap between parent and substrate could have created a beneficial microclimate. Perhaps nest insulation becomes more important as the mass of the incubating parent decreases. While this study is certainly insufficient to determine whether or not small theropod dinosaurs incubated their eggs, it does seem to support their capacity to do so even in the partially buried nest structures that have been identified.

The slope of the best-fit lines for egg temperatures, indoors and outdoors, were similar when measured during the first hour and from hours 8 to 48 . The normalized dot product of the indoor and outdoor vectors over the first hour was 0.987 , and it was 0.992 for the latter 40 hour segment. This suggests comparable rates of change whether indoors or outdoors (if normalized dot product $=1$, then the lines are exactly parallel). It appears that overall the eggs increased toward surrogate temperature largely independent of outdoor variation. During the 48 hour outdoor trials, there appear to 
be slight increases or decreases in temperature that could perhaps correspond to the ambient increase or decrease in the previous 8 hours (figure 4). Despite this lag, the eggs remained closer to surrogate than outdoor ambient temperatures. It seems that the indoor experiment should be an acceptable testing analogue given the similar overall rates of change.

It is important to note that while partially buried eggs received a significant temperature boost from the surrogate, depths below $15 \mathrm{~cm}$ showed little change in energy. Below this thermal-input threshold there is certainly a point at which buried eggs would not receive any heat-related benefit from an incubating adult. Though the top $15 \mathrm{~cm}$ was critical in this experiment, that thermal input threshold is likely dependent upon the mass of the incubating parent, climate, and nest structure. A parent incubating eggs buried in layers at different depths in the sediment would see eggs at varied temperatures. Presumably this would lead to asynchronous hatching if the temperature banding and egg layers were distinct enough.

Relatedly, recent research by Yang et al. (2019b) suggests that oviraptorosaur nests may have been incompatible with contact incubation. The authors reconstruct a volcano-shaped multitiered nest that they argue was likely too large for the adult to effectively cover with its body. Due to the stacked arrangement of eggs, the authors also thought it unlikely that a parent could effectively contact each egg in the clutch. Eggs were layered within the nest in distinct rings, with their blunt ends exposed to the inner air gap of the structure. Other researchers suggest that oviraptorosaurs did contact incubate, or at least brood (Norell et al. 2018). Their newly described specimen, consisting of an adult-associated Citipati osmolskae clutch, shows the same brooding posture described in other nesting oviraptorosaurs. Results obtained from this $T$. formosus nest study suggest that if an adult oviraptorosaur could comfortably cover the nest, there might still be a noticeable temperature gradient due to the depth of the nest, the adult heat source being at the top, and hot air's propensity to rise.

Due to this gradient, oviraptorosaur eggs at the bottom of a clutch may have experienced different temperatures than those at the top. Distinct temperature zones could have possibly affected hatching synchrony. If the eggs all began incubation at the same time, the uppermost eggs might have developed more quickly. However, the lower eggs were almost certainly the first to be laid. These eggs may have hatched first if incubation began before the clutch was complete. Yang et al. (2019a) describe embryonic oviraptorosaur remains that seem to support hatching asynchrony through more-developed bottom eggs. This does beg the question of the architectural stability of a stacked egg nest in which the bottom layer hatches first. It is also important to note that hatching synchrony could have varied significantly among species of oviraptorosaurs. Yang et al. (2019b) note that their model does not readily align with any modern-day nests. It is even possible that a temperature gradient could have reduced hatching time discrepancy too, as the bottom eggs (though laid first) might have experienced cooler temperatures than their later-laid but warmer upper-level siblings.

Aside from keeping eggs closer to surrogate than ambient temperatures, another measure of efficiency for this study was the amount of energy used during the trials. If excessive electrical energy had been needed to warm the eggs, that would raise concerns about the calorie requirements for an adult dinosaur incubating in this manner. The indoor trials averaged $545 \mathrm{kcal} /$ day while outdoors averaged $438 \mathrm{kcal} /$ day. Surprisingly, fewer calories were used outside than inside, perhaps because the surrogate sealed better with the ground outside, being slightly wider than the sediment box used indoors. These values do not seem to be prohibitively high considering that emus have been measured to expend between 645 and $813 \mathrm{kcal} /$ day while incubating (Buttemer and Dawson 1989).

Evidence indicates that the incubation periods in T. formosus would have been around 74 days (Varricchio et al. 2018) compared with only 56 days for emus (Buttemer and Dawson 1989). Total calories expended by the incubating emu during the period of attendance, using averaged values, yields 40,824 kcal. This experiment, if run for 74 days using the higher-end caloric requirements, gives 40,330 
kcal. The convergence here, of course, does not suggest that $T$. formosus and emus might expend the same amount of energy while incubating, but rather that the energy used for the experiment does not appear to be exceedingly high. If an incubating T. formosus did use a similar amount of daily energy (average $729 \mathrm{kcal}$ ) as an incubating emu, then its total caloric expenditure for the incubation period would be around 53,946 kcal. Still, proportionally, a $50 \mathrm{~kg}$ T. formosus spending $53,946 \mathrm{kcal}$ is similar to a $41.45 \mathrm{~kg}$ emu (averaged mass of incubating emus from Buttemer and Dawson [1989]) spending 40,824 kcal: $1079 \mathrm{kcal} / \mathrm{kg}$ versus 985 $\mathrm{kcal} / \mathrm{kg}$. These comparisons would certainly benefit from more rigorous testing, but the longer incubation period suggested for $T$. formosus does not seem to require excessive caloric expenditure.

It has been suggested that perhaps theropod dinosaurs, even smaller ones, could have been too heavy to safely provide contact incubation for their eggs (Deeming and Mayr 2018). In this study the chicken eggs were able to safely sit under the $19 \mathrm{~kg}$ water bath, an amount above their calculated load mass (Ar et al. 1979). Of course, a substantial portion of the incubator's weight rested on the ground, but perhaps a similar strategy could have been employed by brooding dinosaurs. Certain postures would allow the fraction of an adult's mass not supported by limbs and ground to be distributed among all eggs in their clutch, substantially reducing pressure applied to any individual egg. As such, a comparison of eggload mass and adult mass could possibly be improved by dividing the adult mass by probable number of adult-contacted eggs in the clutch. This consideration takes distributed force and resulting pressure into account, the same way that a single nail can easily penetrate skin, but you can lie on hundreds of nails without any punctures - such as with the classic bed of nails demonstration. Research by Zhao and Ma (1997) shows that eggs from troodontids were oriented in such a way as to maximize their load-bearing strength. Additionally, it is possible that adults directed a sizable portion of their weight to the ground via contact between the ground surface and two or four limbs. Such a resting posture could be similar to that shown in theropod trace fossils (Milner et al. 2009).

Recent research shows that eggs belonging to the ootaxa Spheroolithidae, Megaloolithidae, and Faveoloolithidae were frequently associated with specific sediment profiles (Tanaka et al. 2018). On the other hand, troodontid eggs (Prismatoolithidae) were not affiliated with any particular lithology. This lack of preference was also true for oviraptorosaurs, enantiornithines, and neornithes. The authors suggest that this discrepancy corresponds to incubation modes, that burial and mound nesters were discerning with nesting sediments, while contact incubators were not. This could suggest that perfectly matching sediments when modeling contact incubation behavior may be unnecessary.

Troodontid fossil material has been found at $76.7^{\circ} \mathrm{N}$, latitudes well within the Arctic Circle (Fiorillo et al. 2009). Tanaka et al. (2018) also investigated likely nesting habits at these polar paleolatitudes. The authors suggest that dinosaur fossils from these latitudes correspond to species exhibiting mound nesting or partial burial. Paleoclimate data from similar paleolatitudes suggest a cold weather average of $3^{\circ} \mathrm{C}$, warm weather average of $19^{\circ} \mathrm{C}$, and an annual average of $10^{\circ} \mathrm{C}$ (Golovneva 2000). It seems unlikely that open-faced nests could have worked at these temperatures without contact incubation to warm them. While mound nesting is a possibility in these environments (Tanaka et al. 2018), no evidence supporting mound nesting has yet been found for troodontids (Varricchio et al. 1999).

Path from Ectothermic Guarding to Contact Incubation.-While it is still debated whether contact incubating behavior and partially buried eggs overlapped, this study indicates that it is possible that contact incubation of partially buried eggs conferred a benefit. This potentially opens up a simple model for the evolution of the subaerial incubation condition that modern birds have elaborated on to great effect. First, the ancestral condition is assumed to be the guarding of subterranean eggs. Plenty of modern animals guard buried eggs, including crocodilians and megapodes (Jones et al. 1995; Thorbjarnarson 1996). Buried nests also appear to be relatively common 


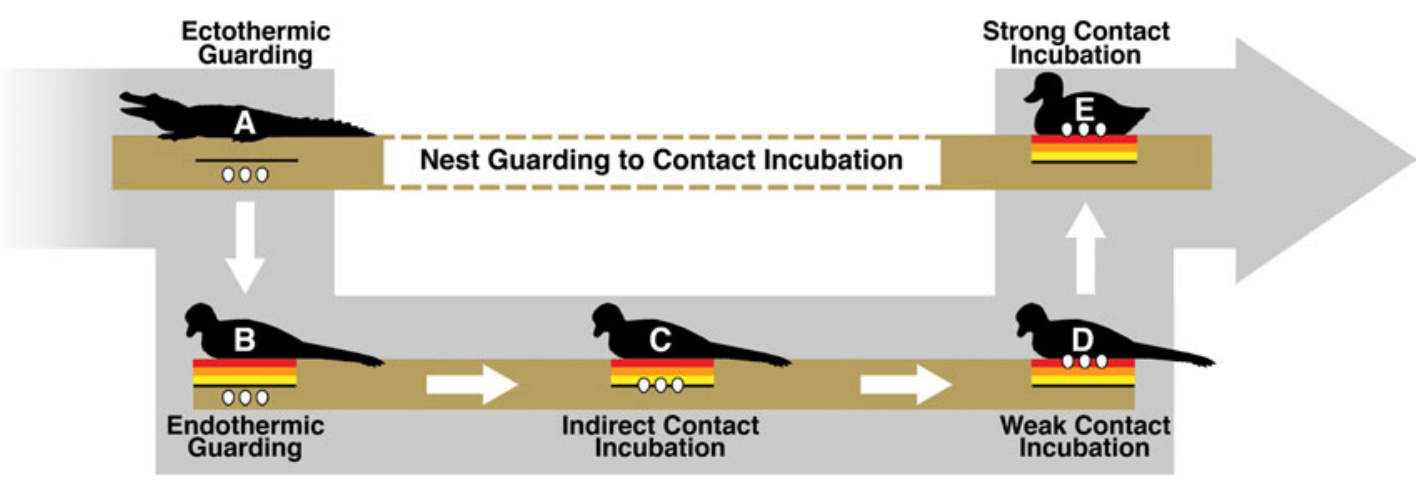

FIGURE 6. Illustration of a potential avenue for the evolution of modern strong contact incubation behavior. A, An ectotherm guarding its egg clutch, a frequent habit of both fossil and modern reptiles. B, An endothermic animal guarding its buried clutch and warming the ground below. In B, the eggs would not gain any temperature-related benefit from the adult. However, due to natural variation in burial depth, some nests within a population might eventually be buried close enough to the heating zone that they experience a small temperature increase from the adult body heat, as shown in C. This could be considered indirect contact incubation, where an adult primarily functions as a guard but a small amount of energy is incidentally reaching the buried clutch. Eggs experiencing a slight increase in temperature could feasibly hatch earlier-leaving the clutch and adult vulnerable for a shorter period of time. It is perhaps possible that an adult in this model could provide some insulative benefits from extreme weather conditions, but more likely the ground is doing the bulk of the thermoregulatory work. Eventually indirect contact incubation could lead to weak contact incubation, such as in D. Partially buried eggs within a troodontid nest would fall into this weak contact incubation category, where eggs gain a significant amount of energy from the adult but are not yet in a fully subaerial position. E, Strong contact incubation, such as in most modern birds, where eggs can experience maximum energy input and temperature regulation from a contact-incubating adult.

in dinosaurs (Deeming 2006). Hypothetically, there are two behavioral paths that would take an organism from guarding subterranean eggs to contact incubating subaerial eggs. One path would require subaerial egg behavior to evolve before contact incubation. The combination of simple guarding and subaerial eggs seems problematic, as the organism would trade off subterranean protection from predators and temperature fluctuation without gaining any obvious advantages. As merely a guard, the organism itself would not serve to ameliorate any of the temperature-related benefits lost from a subterranean nest.

The second path would have incubation behavior evolve before subaerial eggs. In this scenario, a guarding endothermic adult might slightly warm buried eggs just by spending time in the location of the nest. While certainly not as efficient as the contact incubation of subaerial eggs, even a small amount of energy input into a subterranean nest could help to further increase egg temperatures. Because temperature is often the determining factor of incubation rate and hatchling success (Tombre and Erikstad 1996; Martin et al. 2007; DuRant et al. 2013), a small increase in temperature could confer significant enough advantages over the ancestral state. Figure 6 shows how, given an endothermic adult and natural variation in egg burial depth, modern contact incubation behavior could gradually evolve. Once the trend begins, it is easy to see how indirect incubation could lead to weak and finally strong contact incubation behaviors. Eggs buried closer to the surface would gain increasing temperature benefits without sacrificing parental protection. Contact incubation does require significant sacrifices from the parent though, as it becomes more vulnerable to predation and less able to forage for food. It is not suggested that this entire transition occurred only once or solely within nonavian dinosaurs, as buried (Kurochkin et al. 2013) and partially buried (Fernandez et al. 2013) eggs are found in fossil birds.

\section{Conclusion}

Birds could not have evolved such complex and varied nests without first breaking free from the subterranean tendencies of their reptile ancestors. Our understanding of dinosaur 
nesting habits is complicated by their position between these two very different groups. The blueprint for subaerial nesting behavior had to begin somewhere, and it is possible that dinosaurs were the pioneers. The partially buried eggs of $T$. formosus might be evidence of intermediate behavior, yet the ability of $T$. formosus to contact incubate in such a system is controversial. Although this simple study does little to confirm whether or not contact incubation behavior coincided with partly exposed eggs in theropods, it nevertheless sheds light on dinosaur nesting possibilities. These experiments suggest that the presumed inefficiency of contact incubating partially buried eggs may be misguided, as even half-buried eggs maintained temperatures closer to the surrogate than ambient in multiday trials under conditions likely cooler than those many troodontids would have experienced in the Cretaceous. Additionally, metered electrical input showed that the energy needed to keep the experimental eggs above ambient temperatures was not prohibitively high, as compared with modern emus. Nevertheless, there was a distinct temperature profile within the sediment. A thermal input threshold would likely appear in any nest with partially or fully buried eggs, where eggs buried below that limit would receive little to no warmth from an incubating adult. Still, the fact that even completely buried eggs could benefit from an incubating parent at certain depths implies a possible path for the evolution of subaerial nesting behaviors from more ancestral subterranean ones. Such intermediate nests might not have been as warm or efficient as those of modern birds, but they may have been sufficient to push the behavior forward.

\section{Acknowledgments}

J.H. would like to thank J. M. Hogan and K. Klayton for facility space to run the experiments unhindered, L. B. Huizenga for her relentless support, $\mathrm{T}$. Lucille for assisting in the design and construction of the experimental system, T. Hogan and N. Lee for their thoughtful review of an early draft, S. Wuu for her thorough text edits, and finally E. Behr for his patience and positivity.

\section{Literature Cited}

Alexander, D. E., E. Gong, L. D. Martin, D. A. Burnham, and A. R. Falk. 2010. Model tests of gliding with different hindwing configurations in the four-winged dromaeosaurid Microraptor gui. Proceedings of the National Academy of Sciences USA 107:2972-2976.

Amiot, R., C. Lecuyer, E. Buffetaut, G. Escarguel, F. Fluteau, and F. Martineau. 2006. Oxygen isotopes from biogenic apatites suggest widespread endothermy in Cretaceous dinosaurs. Earth and Planetary Science Letters 246:41-54.

Amiot, R., X. Wang, S. Wang, C. Lécuyer, J.-M. Mazin, J. Mo, J.-P. Flandrois, F. Fourel, X. Wang, X. Xu, Z. Zhang, Z. Zhou, and R. Benson. 2017. $\delta^{18} \mathrm{O}$-derived incubation temperatures of oviraptorosaur eggs. Palaeontology 60:633-647.

Ar, A., H. Rahn, and C. V. Paganelli. 1979. The avian egg: mass and strength. The Condor 81:331.

Barrett, P. M., D. C. Evans, and N. E. Campione. 2015. Evolution of dinosaur epidermal structures. Biology Letters 11: 20150229.

Barrick, R. E., and W. J. Showers. 1994. Thermophysiology of Tyrannosaurus rex: evidence from oxygen isotopes. Science 265: 222-224.

Bennett, S. C. 1996. Aerodynamics and thermoregulatory function of the dorsal sail of Edaphosaurus. Paleobiology 22:496-506.

Burgener, L., E. Hyland, K. W. Huntington, J. R. Kelson, and J. O. Sewall. 2019. Revisiting the equable climate problem during the Late Cretaceous greenhouse using paleosol carbonate clumped isotope temperatures from the Campanian of the Western Interior Basin, USA. Palaeogeography, Palaeoclimatology, Palaeoecology, 516: 244-267.

Buttemer, W. A., and T. J. Dawson. 1989. Body temperature, water flux and estimated energy expenditure of incubating emus (Dromaius novaehollandiae). Comparative Biochemistry and Physiology Part A: Physiology 94: 21-24.

Chiappe, L. M. 2009. Downsized dinosaurs: the evolutionary transition to modern birds. Evolution: Education and Outreach 2:248-256.

Dawson, R. R., D. J. Field, P. M. Hull, D. K. Zelenitsky, F. Therrien, and H. P. Affek. 2020. Eggshell geochemistry reveals ancestral metabolic thermoregulation in Dinosauria. Science Advances 6: eaax9361.

Deeming, D. C. 2006. Ultrastructural and functional morphology of eggshells supports the idea that dinosaur eggs were incubated buried in a substrate. Palaeontology 49:171-185.

Deeming, D. C., and G. Mayr. 2018. Pelvis morphology suggests that early Mesozoic birds were too heavy to contact incubate their eggs. Journal of Evolutionary Biology 31:701-709.

Dodson, P. 1971. Sedimentology and taphonomy of the Oldman Formation (Campanian), Dinosaur Provincial Park, Alberta (Canada). Palaeogeography, Palaeoclimatology, Palaeoecology 10:21-74.

DuRant, S. E., W. A. Hopkins, G. R. Hepp, and J. R. Walters. 2013. Ecological, evolutionary, and conservation implications of incubation temperature-dependent phenotypes in birds. Biological Reviews 88:499-509.

Dyke, G., R. de Kat, C. Palmer, J. van der Kindere, D. Naish, and B. Ganapathisubramani. 2013. Aerodynamic performance of the feathered dinosaur Microraptor and the evolution of feathered flight. Nature Communications 4:1-9.

Eagle, R. A., T. Tutken, T. S. Martin, A. K. Tripati, H. C. Fricke, M. Connely, R. L. Cifelli, and J. M. Eiler. 2011. Dinosaur body temperatures determined from isotopic $\left({ }^{13} \mathrm{C}^{-18} \mathrm{O}\right)$ ordering in fossil biominerals. Science 333:443-445.

Fanti, F., P. J. Currie, and D. Badamgarav. 2012. New specimens of Nemegtomaia from the Baruungoyot and Nemegt formations (Late Cretaceous) of Mongolia. PLoS ONE 7:e31330.

Farlow, J. O., C. V. Thompson, and D. E. Rosner. 1976. Plates of the dinosaur Stegosaurus: forced convection heat loss fins? Science 192:1123-1125. 
Fernandez, M. S., R. A. Garcia, L. Fiorelli, A. Scolaro, R. B. Salvador, C. N. Cotaro, G. W. Kaiser, and G. J. Dyke. 2013. A large accumulation of avian eggs from the Late Cretaceous of Patagonia (Argentina) reveals a novel nesting strategy in Mesozoic birds. PLoS ONE 8:e61030.

Fiorillo, A. R., R. S. Tykoski, P. J. Currie, P. J. McCarthy, and P. Flaig. 2009. Description of two partial Troodon brain cases from the Prince Creek Formation (Upper Cretaceous), North Slope Alaska. Journal of Vertebrate Paleontology 29:178-187.

Freimuth, W. J., and D. J. Varricchio. 2019. Insect trace fossils elucidate depositional environments and sedimentation at a dinosaur nesting site from the Cretaceous (Campanian) Two Medicine Formation of Montana. Palaeogeography, Palaeoclimatology, Palaeoecology 534:109262

Fricke, H. C., and R. R. Rogers. 2000. Multiple taxon-multiple locality approach to providing oxygen isotope evidence for warm-blooded theropod dinosaurs. Geology 28:799-802.

Golovneva, L. B. 2000. The Maastrichtian (Late Cretaceous) climate in the Northern Hemisphere. Geological Society of London Special Publication 181:43-54.

Gomez, F., and R. Miikkulainen. 1997. Incremental evolution of complex general behavior. Adaptive Behavior 5:317-342.

Gould, J. L. 1982. Ethology: the mechanisms and evolution of behavior. Norton, New York.

Grellet-Tinner, G., L. M. Chiappe, P. J. Currie, E. B. Koppelhus, M. A. Shugar, and J. L. Wright. 2004. Dinosaur eggs and nesting: implications for understanding the origin of birds. Pp. 185-214 in P. J. Currie, E. B. Koppelhus, M. A. Shugar, and J. L. Wright, eds. Feathered dragons: studies on the transition from dinosaurs to birds. Indiana University Press, Bloomington.

Grellet-Tinner, G., L. Chiappe, M. Norell, and D. Bottjer. 2006. Dinosaur eggs and nesting behaviors: a paleobiological investigation. Palaeogeography, Palaeoclimatology, Palaeoecology 232:294-321.

Hassan, S. M., A. A. Siam, M. E. Mady, and A. L. Cartwright. 2004. Incubation temperature for ostrich (Struthio camelus) eggs. Poultry Science 83:495-499.

Hopp, T. P., and M. J. Orsen. 2004. Dinosaur brooding behavior and the origin of flight feathers. P. 234 in P. J. Currie, E. B. Koppelhus, M. A. Shugar, and J. L. Wright, eds. Feathered dragons: studies on the transition from dinosaurs to birds. 234. Indiana University Press, Bloomington.

Horner, J. R., and D. B. Weishampel. 1988. A comparative embryological study of two ornithischian dinosaurs. Nature 332:256-257.

[ICZN] International Commission on Zoological Nomenclature. 1999. International code of zoological nomenclature, 4 th edition. International Trust for Zoological Nomenclature, London. https://www.iczn.org/the-code/the-international-code-of-zoological-nomenclature/the-code-online.

Jones, D. N., W. R. J. Dekker, and C. S. Roselaar. 1995. The Megapodes, megapodiidae, bird families of the world. Oxford University Press. Oxford.

Jones, T. D., and N. R. Geist. 2012. Reproductive biology of dinosaurs. Pp. 603-612 in M. K. Brett-Surman, T. R. Holtz, J. O. Farlow, and B. Walters, eds. The complete dinosaur, 2nd ed. Indiana University Press, Bloomington.

Kottek, M., J. Grieser, C. Beck, B. Rudolf, and F. Rubel. 2006. World map of the Köppen-Geiger climate classification updated. Meteorologische Zeitschrift 15:259-263.

Kurochkin, E. N., S. Chatterjee, and K. E. Mikhailov. 2013. An embryonic enantiornithine bird and associated eggs from the Cretaceous of Mongolia. Paleontological Journal 47:1252-1269.

Lorenz, K. Z. 1958. The evolution of behavior. Scientific American. 199:67-82

Martin, A. J., and D. J. Varricchio. 2011. Paleoecological utility of insect trace fossils in dinosaur nesting sites of the Two Medicine Formation (Campanian), Choteau, Montana. Historical Biology 23:15-25.
Martin, T. E., S. K. Auer, R. D. Bassar, A. M. Niklison, and P. Lloyd. 2007. Geographic variation in avia incubation periods and parental influences on embryonic temperature. Evolution 61:25582569 .

Milner, A. R. C., J. D. Harris, M. G. Lockley, J. I. Kirkland, and N. A. Matthews. 2009. Bird-like anatomy, posture, and behavior revealed by an Early Jurassic theropod dinosaur resting trace. PLoS ONE 4:e4591.

Norell, M. A., J. M. Clark, D. Demberelyin, B. Rhinchen, L. M. Chiappe, A. R. Davidson, and M. J. Novacek. 1994. A theropod dinosaur embryo and the affinities of the Flaming Cliffs dinosaur eggs. Science 266:779-782.

Norell, M. A., J. M. Clark, L. M. Chiappe, and D. Dashzeveg. 1995. A nesting dinosaur. Nature 378:774-776.

Norell, M. A., J. M. Clark, and L. M. Chiappe. 2001. An embryonic oviraptorid (Dinosauria: Theropoda) from the Upper Cretaceous of Mongolia. American Museum Novitates 2001:1-20.

Norell, M. A., A. M. Balanoff, D. E. Barta, and G. M. Erickson. 2018. A second specimen of Citipati osmolskae associated with a nest of eggs from Ukhaa Tolgod, Omnogov Aimag, Mongolia. American Museum Novitates 3899:1-44.

Palmer, C. 2014. The aerodynamics of gliding flight and its application to the arboreal flight of the Chinese feathered dinosaur Microraptor. Biological Journal of the Linnean Society 113:828-835.

Rahn, H., J. Krog, and F. Mehlum. 1983. Microclimate of the nest and egg water loss of the eider Somateria mollissima and other waterfowl in Spitsbergen. Polar Research 1:171-183.

Retallack, G. J., and D. L. Wolberg. 1997. Dinosaurs and dirt. Pp. 345-359 in D. L. Wolberg, E. Stump, and G. D. Rosenberg, eds. DinoFest International: Proceedings of a Symposium Sponsored By Arizona State University. Academy of Natural Sciences. Philadelphia.

Ruben, J., T. Jones, and N. Geist. 2003. Respiratory and reproductive paleophysiology of dinosaurs and early birds. Physiological and Biochemical Zoology 76:141-164.

Stahlschmidt, Z. R., and D. F. Denardo. 2009. Effect of nest temperature on egg-brooding dynamics in Children's pythons. Physiology and Behavior 98:302-306.

Szczerbińska, D., D. Majewska, Z. Tarasewicz, A. Danczak, and L. Ligocki. 2003. Hatchability of emu (Dromaius novaehollandiae) eggs in relation to incubation temperature. Electronic Journal of Polish Agricultural Universities, Animal Husbandry 6.

Tanaka, K., D. K. Zelenitsky, F. Therrien, and Y. Kobayashi. 2018. Nest substrate reflects incubation style in extant archosaurs with implications for dinosaur nesting habits. Scientific Reports 8:1-10

Thorbjarnarson, J. B. 1996. Reproductive characteristics of the order Crocodylia. Herpetologica 52:8-24.

Tombre, I. M., and K. E. Erikstad. 1996. An experimental study of incubation effort in high-Arctic barnacle geese. Journal of Animal Ecology 65:325-331

van der Reest, A. J., and P. J. Currie. 2017. Troodontids (Theropoda) from the Dinosaur Park Formation, Alberta, with a description of a unique new taxon: implications for deinonychosaur diversity in North America. Canadian Journal of Earth Sciences 54:919-935.

Varricchio, D. J. 1993. Bone microstructure of the Upper Cretaceous theropod dinosaur Troodon formosus. Journal of Vertebrate Paleontology 13:99-104.

Varricchio, D. J., and F. D. Jackson. 2016. Reproduction in Mesozoic birds and evolution of the modern avian reproductive mode. The Auk 133:654-684.

Varricchio, D. J., F. Jackson, J. J. Borkowski, and J. R. Horner. 1997. Nest and egg clutches of the dinosaur Troodon formosus and the evolution of avian reproductive traits. Nature 385:247-250. 
Varricchio, D. J., F. Jackson, and C. N. Trueman. 1999. A nesting trace with eggs for the Cretaceous theropod dinosaur Troodon formosus. Journal of Vertebrate Paleontology 19:91-100.

Varricchio, D. J., J. R. Horner, and F. D. Jackson. 2002. Embryos and eggs for the Cretaceous theropod dinosaur Troodon formosus. Journal of Vertebrate Paleontology 22:564-576.

Varricchio, D. J., F. D. Jackson, R. A. Jackson, and D. K. Zelenitsky. 2013. Porosity and water vapor conductance of two Troodon for mosus eggs: an assessment of incubation strategy in a maniraptoran dinosaur. Paleobiology 39:278-296.

Varricchio, D. J., M. Kundrat, and J. Hogan. 2018. An intermediate incubation period and primitive brooding in a theropod dinosaur. Scientific Reports 8:1-6.
Wesołowski, T. 2004. The origin of parental care in birds: a reassessment. Behavioral Ecology 15:520-523.

Yang, T. R., T. Engler, J. N. Lallensack, A. Samathi, M. Makowska, and B. Schillinger. 2019a. Hatching asynchrony in oviraptorid dinosaurs sheds light on their unique nesting biology. Integrative Organismal Biology 1:obz030.

Yang, T. R., J. Wiemann, L. Xu, Y.-N. Cheng, X. Wu, and M. Sander. 2019b. Reconstruction of oviraptorid clutches illuminates their unique nesting biology. Acta Palaeontologica Polonica 64. doi: 10.4202/app.00497.2018.

Zhao, Z. K., and H. Z. Ma. 1997. Biomechanical properties of dinosaur eggshells (VI)-the stability of dinosaur eggshell under external pressure. Vertebrata PalAsiatica 35:96-101. 